\title{
Kloning Gen Transcriptional Activator Protein dan Replication- Associated Protein dari Squash leaf curl China virus Penyebab Penyakit Daun Kuning pada Tanaman Mentimun
}

\author{
Cloning of Transcriptional Activator Protein and Replication- \\ Associated Protein Genes of Squash leaf curl China virus The Causal \\ Agent of Yellow Leaf Disease on Cucumber
}

\author{
Ni Nengah Putri Adnyani ${ }^{1}$ I Dewa Made Putra Wiratama ${ }^{1}$, \\ I Gede Rai Maya Temaja ${ }^{1 *}$, Sari Nurulita ${ }^{2}$, Gede Suastika ${ }^{2}$ \\ ${ }^{1}$ Universitas Udayana, Denpasar, Bali 80225 \\ ${ }^{2}$ Institut Pertanian Bogor, Bogor 16680
}

\begin{abstract}
ABSTRAK
Penyakit daun kuning yang disebabkan oleh Squash leaf curl China virus (SLCCNV; Begomovirus) merupakan penyakit penting pada Cucurbitaceae yang terjadi di beberapa negara. Gejala yang mirip berupa daun keriting kuning ditemukan pada tanaman mentimun di Tabanan, Bali. Penelitian bertujuan untuk mendapatkan klon gen Transcriptional Activator Protein (TrAp) dan Replication-Associated Protein (Rep) SLCCNV isolat Indonesia. Pasangan primer universal Begomovirus SPG1/SPG2 digunakan untuk mengamplifikasi fragmen DNA Begomovirus yang mencakup gen TrAp dan Rep. Kloning amplikon berukuran $\pm 912 \mathrm{pb}$ menggunakan metode TA-kloning pada vektor pTZ57R/T menghasilkan plasmid rekombinan pTZ-SLCCNV. Plasmid rekombinan pTZ-SLCCNV berhasil dikonfirmasi melalui koloni PCR dan perunutan DNA. Hasil analisis sikuen nukleotida pTZ-SLCCNV menunjukkan homologi yang tinggi (98\%) antara SLCCNV isolat mentimun dari Bali dengan SLCCNV isolat labu dari Malaysia.
\end{abstract}

Kata kunci: Begomovirus, plasmid rekombinan, primer universal, sikuen nukleotida

\begin{abstract}
Yellow disease on Cucurbitaceae caused by Squash leaf curl China virus (SLCCNV; Begomovirus) is an important disease in many countries. Typical yellow leaf curl symptoms was found on cucumber in Tabanan, Bali. The objective of this research is to clone Transcriptional Activator Protein (TrAp) and Replication-Associated Protein (Rep) of SLCCNV Indonesian isolate. Universal primer for Begomovirus, i.e. SPG1/SPG2 was used to amplify DNA fragment of Begomovirus which cover the TrAp and Rep gene. The amplicon of $\pm 912 \mathrm{bp}$ in size was then cloned into $\mathrm{pTZ57R/T}$ plasmid vector by TA-cloning method to obtain plasmid recombinant pTZ-SLCCNV. The plasmid recombinant was successfully confirmed by PCR colony and DNA sequencing. The nucleotide sequences analysis of plasmid recombinant showed highest homology (98\%) of the corresponding gene to pumpkin isolate of SLCCNV from Malaysia.
\end{abstract}

Key words: Begomovirus, recombinant plasmid, universal primer, nucleotide sequences

*Alamat penulis korespondensi: Program Studi Bioteknologi Pertanian, Program Pascasarjana, Universitas Udayana. Jalan PB. Sudirman, Denpasar, Bali 80225

Tel: 0361-223797, Faks: 0361-247962; surel: raitemaja@unud.ac.id 


\section{PENDAHULUAN}

Penyakit daun kuning merupakan salah satu penyakit penting pada tanaman mentimun (Cucumis sativus). Penyakit daun kuning pada mentimun yang berasosiasi dengan Squash leaf curl China virus (SLCCNV) di Bali dilaporkan oleh Wiratama et al. (2015) dan Haerunisa et al. (2016). Sebelumnya, SLCCNV pertama kali dilaporkan menginfeksi tanaman labu (Cucurbita pepo) di Pakistan (Tahir et al. 2010) dan sampai saat ini telah menyebar ke Malaysia, Cina, Vietnam, Filipina, India, dan Thailand (CABI 2014).

Penyakit daun kuning pada mentimun tergolong penyakit baru tetapi berpotensi menyebabkan kehilangan hasil pada tanaman yang terinfeksi. Oleh karena itu diperlukan pemantauan penyakit untuk mencegah penyebaran penyakit tersebut ke daerahdaerah lain. Pelaksanaan pemantauan penyakit di lapangan secara berkelanjutan memerlukan dukungan teknik deteksi yang cepat dan tepat. Enzyme-linked Immunosorbent Assay (ELISA) merupakan teknik deteksi berdasarkan karakter serologi yang banyak dilakukan untuk pemantauan virus di lapangan dalam jumlah yang banyak (He 2013). Sayangnya, antiserum spesifik SLCCNV yang diperlukan untuk ELISA belum tersedia secara komersial.

Antiserum dengan kualitas yang baik dapat diperoleh melalui teknologi recombinant protein overexpression (Gustafsson et al. 2012). Kloning DNA adalah teknologi dasar dalam pembuatan DNA rekombinan virus yang akan digunakan selanjutnya dalam teknologi recombinant protein overexpression (Florentino et al. 2008). Penelitian dilakukan untuk menyiapkan klon DNA SLCCNV isolat Indonesia yang selanjutnya dapat digunakan untuk pembuatan recombinant protein overexpression dalam rangka produksi antiserum sebagai alat deteksi SLCNNV.

\section{BAHAN DAN METODE}

\section{Deteksi SLCCNV}

DNA total diekstraksi dari daun mentimun yang bergejala menggunakan metode cetyl trimethylammonium bromide buffer (CTAB) (Doyle dan Doyle 1987). DNA virus diamplifikasi menggunakan primer universal Geminivirus SPG1 (F) (5'-CCCCKGTGCGWRAATCCAT-3') dan SPG2(R)(5'-ATCCVAAYWTYCAGGGAGC TAA-3') yang mengamplifikasi bagian gen TrAP dan Rep dengan target amplikon berukuran $\pm 912 \mathrm{pb}$ (Li et al. 2004). Reaksi amplifikasi $25 \mu \mathrm{L}$ terdiri atas $12.5 \mu \mathrm{L}$ GoTaq

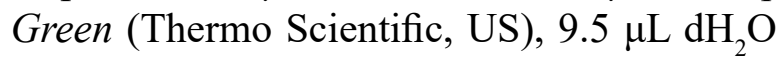
bebas nuklease, primer SPG1 $(10 \mu \mathrm{M})$ dan SPG2 $(10 \mu \mathrm{M})$ masing-masing $1.0 \mu \mathrm{L}$, dan DNA total sebanyak $1 \mu \mathrm{L}$. Program amplifikasi DNA melalui tahap predenaturasi pada suhu $94{ }^{\circ} \mathrm{C}$ selama 5 menit, dilanjutkan dengan 35 siklus yang terdiri atas tahap denaturasi pada suhu $94{ }^{\circ} \mathrm{C}$ selama 1 menit, penempelan primer pada suhu $50{ }^{\circ} \mathrm{C}$ selama 1 menit, sintesis utas DNA pada suhu $72{ }^{\circ} \mathrm{C}$ selama 1 menit, dan pemanjangan utas DNA pada suhu $72^{\circ} \mathrm{C}$ selama 10 menit, dan penyimpanan pada suhu $4{ }^{\circ} \mathrm{C}$.

Fragmen DNA hasil amplifikasi divisualisasi pada gel agarosa $1 \%$ dalam $0.5 x$ bufer TBE (Tris-borate EDTA). Elektoforesis dilakukan pada tegangan 100 volt selama 25 menit dan divisualisasi di bawah $U V$ transiluminator serta didokumentasikan menggunakan kamera digital.

\section{Kloning DNA Target}

Fragmen DNA SLCCNV disisipkan ke dalam plasmid pTZ57R/T melalui reaksi ligasi (Thermo Scientific - US). Reaksi ligasi $(10 \mu \mathrm{L})$ terdiri atas $1 \mu \mathrm{L}$ plasmid vektor pTZ57R/T, $3 \mu \mathrm{L}$ DNA SLCCNV produk PCR, $1 \mu \mathrm{L}$ enzim T4 DNA ligase, $2 \mu \mathrm{L} 5 \mathrm{x}$ bufer ligasi, dan $3 \mu \mathrm{L} \mathrm{dH_{2 }} \mathrm{O}$ bebas nuklease. Reaksi ligasi dilakukan pada suhu $4{ }^{\circ} \mathrm{C}$ selama 16 jam. Hasil ligasi menghasilkan plasmid rekombinan pTZ-SLCCNV.

Transformasi plasmid dilakukan dengan metode heat sock pada suhu $42{ }^{\circ} \mathrm{C}$ ke dalam bakteri E.coli DH5a. Selanjutnya hasil transformasi diinkubasi pada suhu $37{ }^{\circ} \mathrm{C}$ selama 60 menit ke dalam $500 \mu \mathrm{L}$ medium luria bertani (LB) cair ( $2 \%$ tripton, $0.5 \%$ yeast extract, $10 \mathrm{mM} \mathrm{NaCl}$ ), $10 \mu \mathrm{L}$ glukosa, dan 
$2.5 \mu \mathrm{L} \mathrm{MgCl}$. Hasil perbanyakan transforman ditumbuhkan pada medium agar-agar LB $100 \mathrm{~mL}$ yang telah diberi $100 \mu \mathrm{L}$ ampisilin $\left(50 \mu \mathrm{g} \mathrm{mL} \mathrm{m}^{-1}\right)$. Biakan tersebut diinkubasi semalam pada suhu $37^{\circ} \mathrm{C}$.

\section{Konfirmasi Hasil Kloning SLCCNV}

Koloni tunggal berwarna putih hasil tranformasi pada medium diambil dengan tip steril, kemudian dimasukkan ke tabung mikro yang telah diisi dengan komponen reaksi PCR. Reaksi amplifikasi dilakukan menggunakan program yang sama pada saat awal amplifikasi SLCCNV.

Isolasi plasmid dilakukan menggunakan metode alkaly lysis (Sambrook dan Rusel 2001). Plasmid pTZ-SLCCNV dipotong dengan enzim restriksi BamHI dan EcoRI. Reaksi restriksi $(20 \mu \mathrm{L})$ yang terdiri atas $2 \mu \mathrm{L}$ plasmid pTZ-SLCCNV, $0.5 \mu \mathrm{L}$ enzim BamHI (G/GATCC), $2 \mu \mathrm{L}$ 10x bufer BamHI, $0.5 \mu \mathrm{L}$ enzim EcoRI (G/AATTC), $2 \mu \mathrm{L} 10 \mathrm{x}$ bufer EcoRI, $0.5 \mu \mathrm{L}$ BSA dan $12.5 \mu \mathrm{L} \mathrm{dH}_{2} \mathrm{O}$. Reaksi restriksi diinkubasi pada suhu $37{ }^{\circ} \mathrm{C}$ selama 16 jam. Hasil restriksi divisualisasi seperti teknik yang telah diuraikan sebelumnya.

Produk amplifikasi dikirim ke PT. Genetika Science Indonesia untuk dilakukan sikuen nukleotida di First Base Malaysia. Data sikuen nukleotida kemudian dianalisis menggunakan clustalW multiple alignment dengan peranti lunak Bioedit V7.05 dan dilanjutkan dengan analisis filogenetika menggunakan peranti lunak MEGA 6.06.

\section{HASIL}

Sampel daun tanaman mentimun dengan gejala keriting menguning yang diambil dari daerah Tabanan, Bali positif terinfeksi Begomovirus; ditunjukkan dengan munculnya fragmen DNA berukuran $\pm 912 \mathrm{pb}$ sebagai hasil amplifikasi (Gambar 1). DNA amplikon yang berhasil diklonkan ke dalam vektor pTZ57R/T menghasilkan plasmid rekombinan pTZ-SLCCNV. Keberhasilan proses ligasi dapat dilihat dari tumbuhnya koloni bakteri berwarna putih (bakteri rekombinan) pada medium LB (Gambar 2).

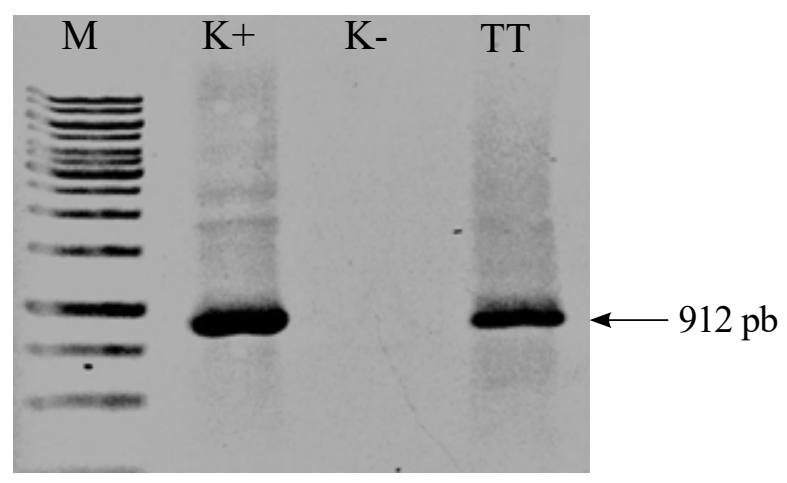

Gambar 1 Amplifikasi DNA target SLCCNV berukuran $\pm 912 \mathrm{pb}$ menggunakan primer universal Geminivirus SPG1/SPG2. M: Penanda DNA (1 kb DNA ladder); K-, kontrol negatif; $\mathrm{K}+$, kontrol positif (sampel tanaman cabai terinfeksi Geminivirus); dan TT, isolat daun mentimun yang positif terserang SLCCNV.

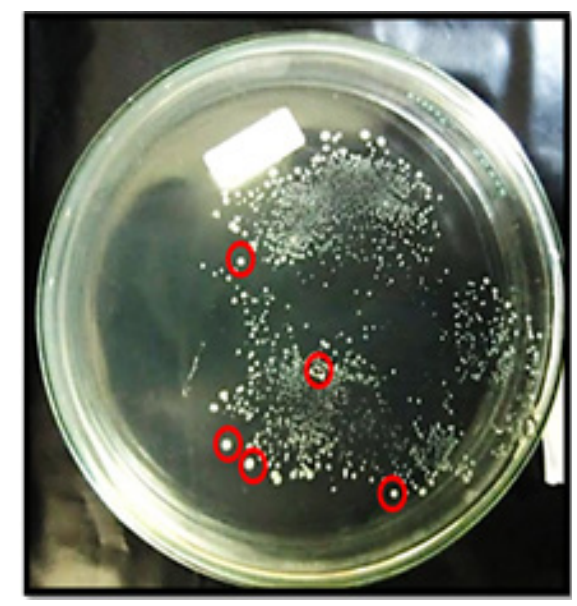

Gambar 2 Koloni bakteri hasil transformasi yang ditumbuhkan pada medium agar-agar luria bertani yang mengandung ampisilin. Lingkaran merah menandakan koloni yang diambil kemudian koloni tersebut di amplifikasi.

Lima koloni bakteri rekombinan berhasil dikonfirmasi dengan PCR menggunakan pasangan primer SPG1/SPG2, yaitu ditunjukkan dengan teramplifikasinya pita DNA berukuran \pm 912 pb (Gambar 3). Lebih lanjut, lima klon pTZ-SLCCNV berhasil diisolasi menghasilkan plasmid DNA berukuran \pm 3798 pb (Gambar 4). Hasil pemotongan plasmid rekombinan pTZ-SLCCNV dengan enzim restriksi EcoRI/BamHI menghasilkan dua pita DNA berukuran sekitar 2886 pb (plasmid vektor 
$\mathrm{pTZ57R/T}$ ) dan $\pm 912 \mathrm{pb}$ (fragmen DNA SLCCNV) (Gambar 5). Dengan demikian, dari penelitian ini berhasil diperoleh lima klon DNA SLCCNV yang berpotensi untuk digunakan dalam tahap penelitian selanjutnya.

Konfirmasi klon DNAlebih lanjut dilakukan melalui analisis sikuen. Analisis kesejajaran sikuen SLCCNV isolat Bali memiliki nilai homologi tertinggi dengan isolat Malaysia, Cina, Vietnam, Filipina, India dan Thailand dengan kisaran sekitar 90.9-98.0\% (Tabel 1). Analisis filogenetika menunjukkan bahwa SLCCNV isolat Bali memiliki hubungan kekerabatan yang dekat dengan SLCCNV dari Malaysia yang menginfeksi tanaman labu (Gambar 6). Beberapa Begomovirus yang juga diketahui menginfeksi tanaman mentimun, seperti Tomato leaf curl New Delhi virus (ToLCNDV) digunakan sebagai pembanding di luar grup karena memiliki tingkat kemiripan lebih rendah dibandingkan dengan SLCCNV.

\section{PEMBAHASAN}

Infeksi Begomovirus pada tanaman mentimun di Indonesia pertama kali ditemukan di daerah Klaten - Jawa Tengah pada tahun 2008 (Mizutani et al. 2011), kemudian di daerah Tegal - Jawa Tengah dan Sleman - Yogyakarta pada tahun 2012 (Septariani et al. 2014). Hasil identifikasi menggunakan sepasang primer Deng A/Deng B oleh Mizutani et al. (2011) dan PAL1v1978/Par1c715 oleh Septariani et al. (2014) diketahui bahwa Begomovirus yang berasosiasi dengan penyakit keriting kuning pada mentimun ialah Tomato leaf curl New Delhi virus (ToLCNDV). Pada penelitian yang lain, Haerunisa et al. (2016) berhasil mengidentifikasi dua spesies virus yang berbeda, yaitu ToLCNDV dan SLCCNV dari sampel mentimun yang berasal dari Bali.

Kloning DNA rekombinan dengan vektor ekspresi merupakan salah satu metode yang banyak digunakan dalam pembuatan antiserum karena memiliki beberapa keunggulan. Teknologi ini diketahui memiliki spesifitas dan kemurnian yang tinggi sehingga dapat mencegah terjadinya reaksi silang dengan protein tanaman (Cotillon et al. 2005). Selain

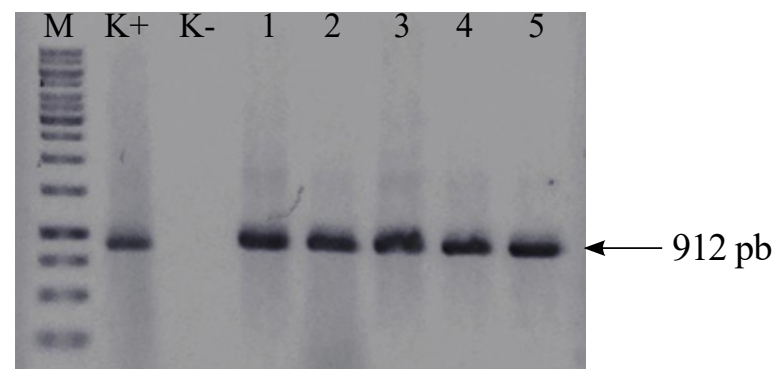

Gambar 3 Hasil PCR koloni klon rekombinan pTZ-SLCCNV. M, Penanda DNA (1 kb DNA ladder; Thermo Scientific); $\mathrm{K}+$, kontrol positif; K-, kontrol negatif; dan 1-5, PCR koloni transforman yang mengandung pTZSLCCNV dengan ukuran pita $\pm 912 \mathrm{pb}$.

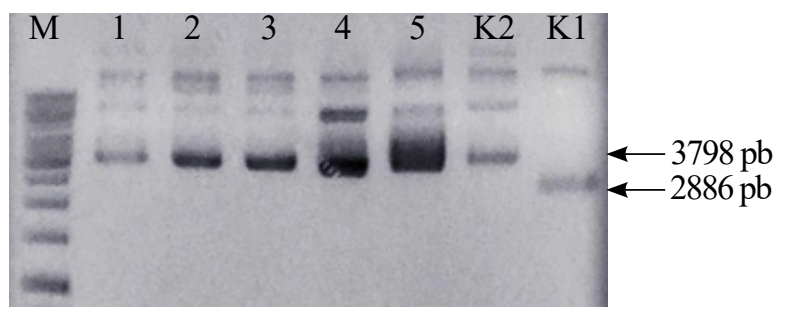

Gambar 4 Hasil isolasi plasmid terhadap klon rekombinan pTZ-SLCCNV. M, Penanda DNA $1 \mathrm{~Kb}$; $1-5$, klon DNA rekombinan SLCCNV tanpa pemotongan enzim restriksi; K2, Kontrol plasmid yang telah tersisipi DNA target (klon rekombinan); dan K1, Kontrol plasmid yang tidak tersisipi.

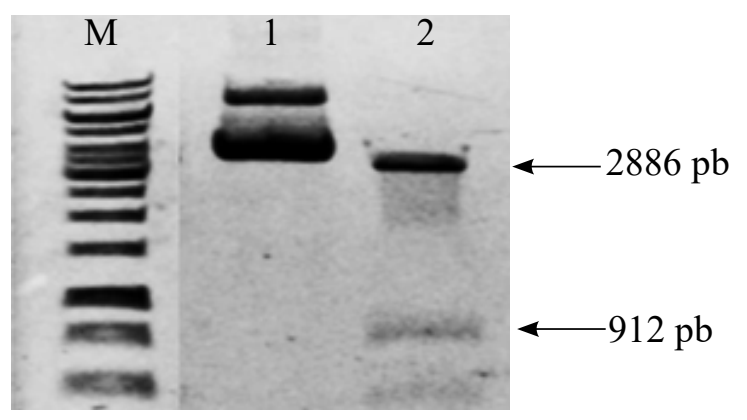

Gambar 5 Pemotongan plasmid rekombinan pTZ-TrAp dan Rep SLCCNV dengan enzim restriksi Bam HI dan EcoRI. M, Penanda DNA (1 kb DNA ladder); 1, pTZ-SLCCNV yang tidak dipotong; dan 2, pTZ-SLCCNV yang berhasil terpotong.

itu, konsentrasi antibodi yang dihasilkan melalui kloning ekspresi pada bakteri $E$. coli mencapai $2 \mathrm{~g} \mathrm{~L}^{-1}$ dan lebih tinggi dibandingkan dengan sistem ekspresi pada khamir, serangga, dan manusia (Verma et al. 1998). Plasmid 
Tabel 1 Tingkat homologi (\%) gen TrAp dan Rep SLCCNV galur Bali dengan SLCCNV galur negara lain yang terdapat pada GenBank

\begin{tabular}{lccccccccccc}
\hline \multicolumn{2}{l}{ Sikuen } & No. Aksesi & 1 & 2 & 3 & 4 & 5 & 6 & 7 & 8 & 9 \\
\hline 1 & pTZ-SLCCNV & & 100 & & & & & & & & \\
2 & SLCCN-Malaysia & EF19740 & 98.0 & 100 & & & & & & & \\
3 & -Cina & AM260206 & 92.3 & 94.2 & 100 & & & & & & \\
4 & -Vietnam & KC857509 & 92.5 & 94.4 & 95.3 & 100 & & & & & \\
5 & -Filipina & EU487031 & 90.9 & 92.7 & 91.7 & 92.6 & 100 & & & & \\
6 & -India & EU573715 & 91.7 & 93.3 & 93.3 & 94.1 & 92.1 & 100 & & & \\
7 & -Thailand & AB330078 & 91.5 & 93.4 & 95.2 & 96.8 & 91.9 & 93.9 & 100 & & \\
8 & ToLCNDV-India & KC465466 & 81.8 & 83.3 & 82.8 & 82.8 & 81.8 & 82.0 & 83.0 & 100 & \\
9 & TYLCV-Cina & GU434143 & 69.9 & 71.3 & 71.7 & 72.3 & 72.0 & 71.7 & 72.8 & 71.7 & 100 \\
\hline
\end{tabular}

Ket: ToLCNDV-India dan TYLCV-Cina sebagai pembanding di luar grup.
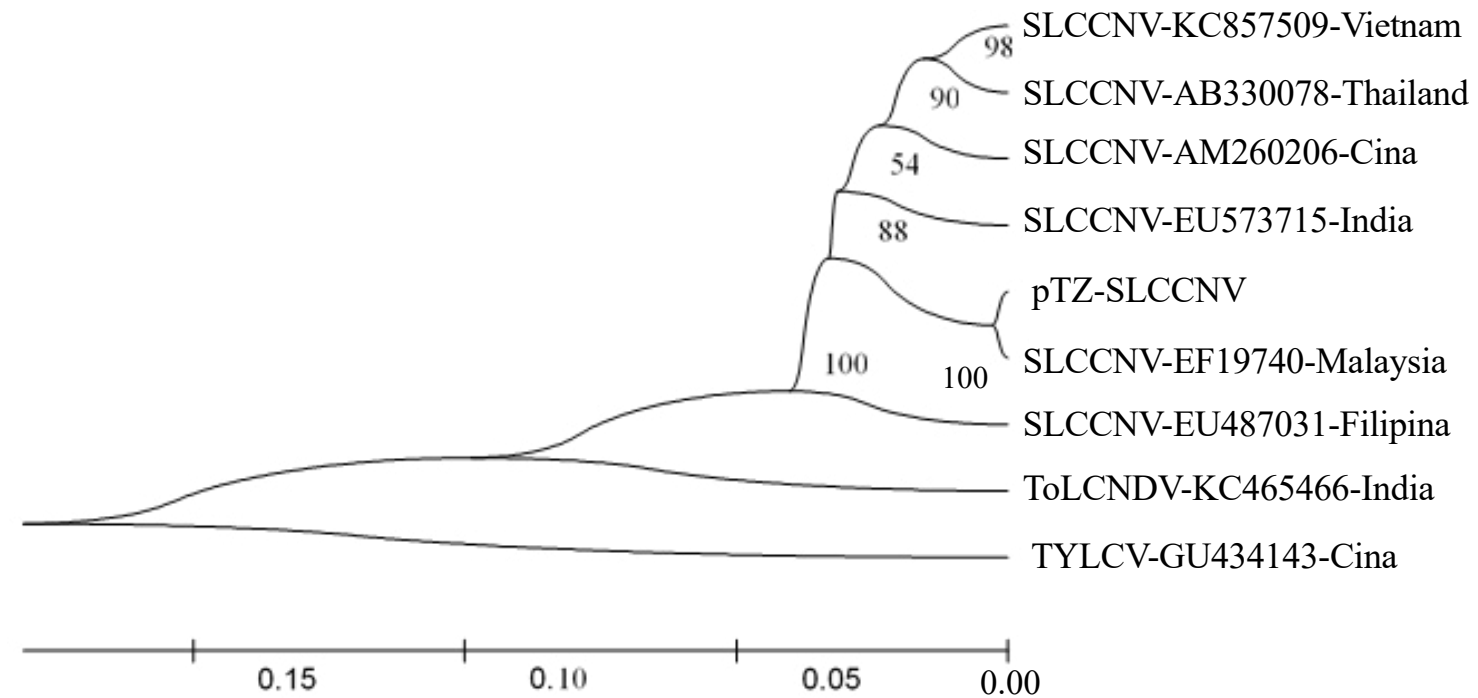

Gambar 6 Pohon filogenetika klon gen TrAp dan Rep SLCCNV galur Bali dibandingkan dengan galur-galur dari beberapa negara. Tomato leaf curl New Delhi virus asal India (KC465466) dan Tomato yellow leaf curl virus asal Cina (GU434143) digunakan sebagai pembanding dari luar grup. Pohon filogenetika dikonstruksi menggunakan perangkat lunak MEGA versi 6.06 dengan Algoritma UPGMA menggunakan 1000 kali bootstrap.

rekombinan pTZ-SLCCNV yang dihasilkan pada penelitian ini berasal dari TA kloning yang dapat digunakan sebagai cetakan untuk kloning ekspresi. Metode yang sama telah berhasil dilakukan untuk ekspresi protein selubung pada Sugarcane streak mosaic virus (Hamdayanty et al. 2016) dan Tomato infectious chlorosis virus (Kurniawati et al. 2015).

Penyebab penyakit daun kuning yang menginfeksi tanaman mentimun di Bali berhasil dideteksi menggunakan metode PCR kloning. Hasil analisis perunutan nukleotida menunjukkan bahwa penyakit daun kuning pada mentimun berasosiasi dengan SLCCNV dari kelompok Begomovirus. Lebih lanjut, plasmid rekombinan pTZ-SLCCNV yang dihasilkan pada penelitian ini dapat digunakan untuk pembuatan antiserum yang dapat diperlukan untuk deteksi rutin SLCCNV.

\section{DAFTAR PUSTAKA}

CABI. 2014. Distribution map of plant disease. [diakses pada: 8 Februari 2018]. Tersedia pada: https://www.cabdirect.org/cabdirect/ abstract/20143369338.

Cotillon AC, Desbiez C, Bouyer S, WipfScheibel C, Gros C, Delecolle B, Lecoq H. 
2005. Production of a polyclonal antiserum against the coat protein of Cucurbit yellow stunting disorder crinivirus expressed in Escherichia coli. EPPO Bulletin. 35(1):99103. DOI: https://doi.org/10.1111/j.13652338.2005.00804.x.

Doyle JJ, Doyle JL. 1987. A rapid DNA isolation of procedure for small quantities of fresh leaf tissue. Phytochem Bull. 19:11-19.

Florentino LH, Santos AA, Zerbini FM, Fontes EPB. 2008. Begomoviruses: molecular cloning and identification of replication origin. Foster GD, Johansen IE, Hong Y, Nagy PD, Editor. Plant Virology Protocols. Totowa, NJ (US): Humana Press. Hlm. 145-166.

Gustafsson C, Minshull J, Govindarajan S, Ness J, Villalobos A, Welch M. 2012. Engineering genes for predictable protein expression. Protein Expres Purif. 83(1): 37-46. DOI: http://dx.doi.org/10.1016/j. pep.2012.02.013

Haerunisa R, Suastika G, Damayanti TA. 2016. Identifikasi Begomovirus yang berasosiasi dengan penyakit kuning pada mentimun di Jawa Barat dan Bali. J Hort Indon 7(1): 9-20. http://dx.doi.org/10.29244/jhi.7.1.9-20. Hamdayanty H, Hidayat SH, Damayanti TA. 2016. Expression of recombinant Sugarcane streak mosaic virus coat protein gene in Escherichia coli. Hayati 23(3):111116. DOI: https://doi.org/10.1016/j. hjb.2016.11.001.

$\mathrm{He}$ J. 2013. Practical guide to ELISA development. Di dalam: Wild D, John $\mathrm{R}$, Sheehan $\mathrm{C}$, Binder He J, editor. The Immunoassay Handbook: Theory and Applications of Ligand Binding, ELISA and Related Techniques. Ed: $4^{\text {th }}$. Oxford (GB): Elsevier. Hlm 381-393. DOI: https://doi. org/10.1016/B978-0-08-097037-0.00025-7.
Kurniawati F, Suastika G, Giyanto G. 2015. Ekspresi gen protein selubung Tomato infectious chlorosis virus pada Escherichia coli. JHPT Tropika. 15(2):114-121.

Li R, Salih S, Hurtt S. 2004. Detection of gemini viruses in sweet potato by polymerase chain reaction. Plant Dis. 88(12):1347-1351. DOI: https://doi. org/10.1094/PDIS.2004.88.12.1347.

Mizutani T, Daryono BS, Ikegami M, Natsuaki KT. 2011. First report of Tomato leaf curl New Delhi virus infecting cucumber in Central Java, Indonesia. Plant Disease, 95(11):1485-1485. DOI: https://doi. org/10.1094/PDIS-03-11-0196.

Sambrook J, Russel DW. 2001. Molecular Cloning: A Laboratory Manual. New York (US): Cold Spring Harbor Laboratory Press.

Septariani DN, Hidayat SH, Nurhayati E. 2014. Identifikasi penyebab penyakit daun keriting pada tanaman mentimun. JHPT Tropika 14(1):80-86.

Tahir M, Haider MS, Briddon RW. 2010. First report of Squash leaf curl China virus in Pakistan. Aus Plant Dis Notes. 5:21-24. DOI: https://doi.org/10.1071/DN10009.

Verma R, Boleti E, George AJ. 1998. Antibody engineering: comparison of bacterial, yeast, insect and mammalian expression systems. J Immunol Methods 216(1-2):165-181. DOI: 10.1016/S00221759(98)00077-5.

Wiratama P, Susanta Wirya GNA, Suastika G, Nyana DN. 2015. Laporan Pertama tentang infeksi Begomovirus pada tanaman mentimun di Bali. J Fitopatol Indones. 11(5):175-178. DOI: https://doi. org/10.14692/jfi.11.5.175. 